\title{
Evidência e existência ideal nas Investigações Lógicas de Husserl: uma análise sobre a conexão entre caracteres de ato e a estrutura das idealidades
}

Evidence and ideal existence in Husserl's Logical Investigations: an analysis of the connection between characters of act and the structure of idealities

DOI: $10.12957 / \mathrm{ek} .2018 .28783$

Ms. Yuri José Victor Madalosso joseph.requiem@gmail.com Universidade Estadual de Londrina - PR

Neste artigo, o objetivo geral é entender a relação entre o caráter posicional do conceito de evidência e a tese acerca da existência ideal dos objetos lógicos nas Investigações lógicas (1900-1901) de Edmund Husserl. Especificamente, é mostrar que a problematização da estrutura posicional da evidência e conhecimento categoriais é necessária para a abordagem do conceito de existência ideal; além disso, irá explicitar que as limitações na diferenciação entre qualidade e posicionamento acarretam em dificuldades epistemológicas cruciais; por fim, mostrar a primazia do conceito de "síntese identificante". Inicialmente, se fará a reconstrução do conceito de posicionalidade. Em seguida, será explicitada a concepção de evidência das Investigações Lógicas; logo após será tematizado o conceito de existência ideal para, a seguir, apresentar os principais problemas e, finalmente, será realizado o enfrentamento destas dificuldades pela reconsideração classificatória do conceito de síntese e a reestruturação do conceito de "estado de coisas".

\section{PALAVRAS-Chave Qualidade. Posicionalidade. Evidência. \\ Intuição Categorial. Existência Ideal}


This article aims to understand the relationship between positing character of the concept of evidence and the thesis of the ideal existence of logical objects and categories in Husserl's Logical investigations (1900-1901). Specifically, is to show which the problematization of the positional structure in categorial evidence and knowledge is necessary to the approach to the concept of ideal existence; besides, will explicate which limitations in differentiation between intentional quality and positing cause crucial epistemological difficulties; finally, show the priority of the concept of "identifying synthesis". Primarily, will make a reconstruction of the concept of positing; secondarily, will analyze the conception of evidence in the Logical Investigations; then, will elucidate the concept of ideal existence for, after this, to show the main problems and, finally, will make the facing of these difficulties through the classificatory reconsiderations of the concept of synthesis and the restructuration of the concept of "state of affairs".

\section{KEY-WORDS Quality. Positing. Evidence. Categorial \\ Intuition. Ideal Existence}




\section{Introdução}

O objetivo principal deste artigo é entender as relações entre o caráter posicional do conceito de evidência e a afirmação da tese da existência ideal dos objetos lógicos nas Investigações lógicas. Especificamente, tem como objetivo mostrar que uma abordagem frutífera do problema epistemológico referente aos objetos lógicos passa por uma análise e tematização dos caracteres essenciais do ato de evidência e seus paralelos ideais/categoriais.

Para mostrar a pertinência interpretativa de nossa hipótese, toma-se a seguinte estratégia teórica: em primeiro lugar, iremos reconstruir e analisar os conceitos de ato posicional e qualidade intencional, presentes na Quinta investigação ${ }^{1}$, assim como alguns desenvolvimentos desenvolvidos na Sexta investigação (em especial o capítulo V e em alguns trechos do capítulo VI). Em seguida, iremos reconstruir os principais conceitos de evidência dentro das investigações, em especial os presentes nos Prolegômenos à lógica pura e na Sexta investigação, também no capítulo V. Depois vamos proceder a uma análise das teses que respaldam a afirmação da existência a priori e ideal das essências e objetos lógicos, assim como das categorias.

A análise do texto será feita a seguir, identificando as lacunas teóricas de Husserl no tratamento dos conceitos e temas arrolados acima; em especial, será problematizada a relação entre identificação posicional e síntese/identificação categorial, além do questionamento do conceito de existência ideal vinculado à noção de validade objetiva e realização na dinâmica de preenchimento, as dificuldades em se distinguir o conceito de qualidade intencional do de posicionamento, o tratamento equívoco dos correlatos objetivos dos atos proposicionais e nominais (enquanto posicionais) e a distinção exaustiva entre as esferas real e ideal do conhecimento. Contudo, não se deslindará toda a teoria das objetidades $^{2}$ ideais e das significações, mas unicamente às conclusões e estruturas argumentativas que estão ligadas ao problema aqui tratado.

Tais problemas serão classificados e enfrentados de modo paulatino, para se buscar uma solução contextualizada na obra de 1900-1901. Os resultados

\footnotetext{
1 Doravante, designar-se-á cada parte das Investigações lógicas como Investigação (ões) (por exemplo, a Quinta investigação), e, quando for denotado o conjunto da obra, será pelo termo Investigações. Deste modo, em relação aos Prolegômenos à lógica pura, será usado termo Prolegômenos.

2 Tradução de Gegenständlichkeit feita por Zeljko Loparic e Andrea Maria Altino de Campos Loparic, que justifica seu uso pela razão de que não se pode confundir este conceito com o de "objetividade" (e suas declinações, como "objetal"), que é atributo de todo o conhecimento válido e, principalmente, nas Investigações lógicas, dos objetos ideais (As significações puras: conceitos e proposições, formas categoriais e leis puras da lógica, etc.). Ver em HUSSERL, 1980, p. 20, $\$ 5$, nota de rodapé 32.
} 
alcançados nas análises e explicitações aqui empreendidas direcionam a uma hipótese de solução e correta colocação do problema de assumir o conceito de existência ideal: este problema se colocaria de modo mais pertinente se forem clarificados os conceitos de "síntese" e "síntese identificante/ de identificação", além de uma conexão rigorosamente estruturada dos caracteres descritivos e epistemológicos como condição necessária e anterior à tese realista lógica quanto aos argumentos usados para a sua defesa.

\section{Posicionalidade e qualidade intencional: descrição fenomenológica e função cognitiva}

Nesta seção, será feita a reconstrução do conceito de posicionalidade dada por Husserl; em primeiro lugar, em seu aspecto descritivo; em segundo, em seu aspecto epistemológico. Sobre o primeiro enfoque, não se aprofundará estritamente no tema psicológico descritivo em toda a amplitude que é tratado nas Investigações, mas no que interessa para os objetivos desse artigo.

O conceito de posicionalidade e, em maior detalhamento, de "ato posicional", é delimitado na Quinta investigação, sob o tema da constituição dos atos objetivantes, sejam eles meramente "simbólicos" ou intuitivos; em especial, são os capítulos III e IV que tratam destes problemas classificatórios e descritivos. Além disso, vemos este conceito ser tratado também na Sexta investigação, sob um enfoque epistemológico, mesmo que outro aspecto essencial das vivências intencionais, a saber, a matéria intencional, seja enfatizado no que se chama de "sínteses de preenchimento".

Dadas estas indicações preliminares, define-se como posicionamento ou se caracteriza o ato psíquico (vivência intencional) como uma modificação qualitativa do assentimento, na própria vivência, à existência do objeto intencionado. Um exemplo claro é a diferença entre uma percepção, que toma o objeto correlato enquanto existente, e a afiguração ou imaginação, que toma o objeto intencionado de modo a não considerar este caráter - um ato não posicional. Portanto, é um caráter abstrato do ato, assim como a matéria intencional, pois compõe um todo completo na essência intencional.

Em consequência, os atos objetivantes, isto é, atos que possuem uma matéria especificamente voltada de modo direto ao objeto intencionado, sem intermediários, têm vinculado em sua estrutura um caráter posicional, distinguível de seu direcionamento objetivo específico (a matéria intencional), dado que 
todo ato objetivante é posicional ou não posicional (não necessariamente afirmando o objeto como existente) em algum sentido, ou seja, visa o objeto em caráter de existência ou não.

Isso não significa, entretanto, que esse caráter posicional faça o objeto existir - em outras palavras, dê um caráter ontológico intrínseco ao próprio objeto. Este último é apreendido e vivido por vários modos, mas não entra na consciência: enquanto vivido, pode ser enquanto "existente enquanto vivido" ou de tal modo com que não há interesse algum nesse posicionamento, como é o caso da imaginação. No caso dos atos nominais que acompanham nossa vida linguística, por assim dizer, a existência do objeto é "mantida em suspenso": quando designo um objeto por meio de expressões, não importa se ele exista ou não, ou se eu posso apreendê-lo como existente - enquanto me atenho à vida psíquica voltada puramente às intenções de significação.

Para Husserl, os caracteres qualitativos e de posição possuem relações estruturais próximas, mas não identidade no trânsito de uma a outra. Tal problema remete à classificação dos gêneros e espécies de qualidades intencionais, e as relações essenciais com a matéria intencional. Isso é mostrado na Quinta investigação, nos capítulos III, §24, quando se diferencia entre afirmação, negação e suspensão de crença, por um lado, e a distinção entre representação, juízo e imaginação, por outro (HUSSERL, 1967b, p. 234-235, §24). Contudo, enfrenta tanto a possibilidade de mais classificações ramificadas (como a divisão da qualidade "juízo" em negativo e positivo) ou outros modos de consciência variados (vontade, desejo, espera, etc.). Este problema será debatido durante todo o prosseguimento do capítulo e encontrará dificuldades mais acentuadas na teoria do juízo (capítulo IV) e, em considerações de grande importância para a teoria conhecimento, (capítulo V, acerca dos atos objetivantes) (cf. HUSSERL, 1967b, p. 270 e ss.,§35 e HUSSERL, 1967b, p. 288-289, §38).

Entretanto, Ivana Milnar, em seu artigo La Evidencia en las Investigaciones lógicas: um aporte para una comprensión modal de la experiencia (2013), analisa que a diferenciação entre qualidade intencional e posicionamento só irá ser delimitada com mais rigor a partir da fase transcendental de Husserl, em especial Ideias $I^{\beta}$ (cf. MILNAR, 2013, p. 51). Mesmo que este ponto só seja objeto de discussão nas seções posteriores, a tese de Milnar afirma, de um modo geral, que a diferenciação adequada entre tais caracteres de ato é necessária para fundamentar a concepção fenomenológica de que o conhecimento tem delineamentos modais (possibilidade, modo de consciência).

3 Neste sentido, Husserl, em uma nota de rodapé no capítulo III, §31, afirma que somente em Ideias I é que houve uma ampliação do estudo das modificações qualitativas, o que é chamado, no contexto de 1913, de modificações de neutralidade (HUSSERL, 1967b, p. 259, §31). 
Na Sexta investigação, o caráter posicional é tematizado de modo mais enfático e detalhado no capítulo V, ( $O$ ideal de adequação. Evidência e verdade). Para a série gradual e progressiva em que se desdobra o conhecimento pleno e definitivo dos objetos, de modo mais primário é a matéria intencional que é suporte fundante e delineamentos qualitativos-posicionais não entram em questão (HUSSERL, 2001b, p. 259, §36). Somente na descrição e categorização do ato de evidência é que tal caráter é retomado em uma importância maior. Em vários pontos, por exemplo, do capítulo III, Husserl reafirma que a essência intencional é constituída pela qualidade, matéria e conteúdo intencional intuitivo (que adquire determinações funcionais nas séries graduais de preenchimentos).

\section{A evidência em seus caracteres essenciais - posicionamento e identificação}

Há, nos Prolegômenos à lógica pura, uma tematização do conceito de evidência, motivada pelo tom polêmico e a crítica contra concepções psicologistas de lógica. Contudo, mesmo que provisória, esta tematização contém alguns princípios e conceitos fundamentais que não serão alterados nas Investigações, a saber, o caráter objetivo do conceito de evidência e sua definição básica de "vivência da verdade" e doação originária plena de uma situação objetiva.

No capítulo VIII (Terceiro prejuízo: lógica como teoria da evidência), §§4951, Husserl efetua uma crítica e refutação do que chama de concepção de lógica como teoria da evidência, isto é, a ideia de que esta ciência é dependente da psicologia, em especial, das leis indutivas explicativas ${ }^{4}$ do fenômeno da evidência. ${ }^{5}$ Este fenômeno acompanha todo o juízo verdadeiro, enquanto enunciado e pensado, determinando seu valor de verdade. Assemelha-se, em uma parte, com um critério de verdade, tal como a clara et distincta perceptio de Descartes (HEFFERNAN, 2014, p. 10), e como fundamento explicativo causal de um juízo verdadeiro. Tais perspectivas são compartilhadas por alguns estudiosos do contexto histórico e científico de Husserl, como Sigwart, Wundt, Hoffler

4 Explicação, na fase de produção textual de Husserl de 1900-1901, significa postulação e investigação indutiva de conexões causais entre fenômenos empíricos. "Ciência empírica" e “ciência explicativo-causal”, portanto, são equivalentes. Ver PORTA, 2013, p. 56, 2.

5 Este capítulo trata de uma crítica geral elaborada por Husserl, visando os "prejuízos psicologistas" a que a lógica pura estaria submetida. São eles: a concepção de que a teoria do conhecimento é regida pela psicologia do conhecimento; decorrente deste, o segundo prejuízo é a subsunção da lógica à psicologia, pois, segundo as correntes ditas "psicologistas", os termos usados na lógica são redutíveis a operações psicológicas; por fim, o terceiro é de que a lógica trata das condições psicológicas do conceito de verdade, a saber, de como se produz mentalmente a evidência das leis dessa ciência. 
e Meinong. Segundo Husserl, esta concepção, em seu matiz "moderna", tem como precursor mais próximo o filósofo e economista Stuart Mill.

Husserl não concorda com a concepção de seus contemporâneos, pois o caráter indutivo das leis psicológicas não garante validade nem objetividade requeridas para a construção de uma ciência pura. Toda aplicação empírica de leis lógicas, diz Husserl no $§ 50$, é feita por via indireta, e não por redução "do complexo ao simples", tal como uma ciência natural. Ainda assim, concede um papel prático para a explicação empírica de nossas inferências, mas nunca teorético. Mesmo que o conteúdo objetivo ideal das proposições e conceitos seja cognoscível por meio de nossas faculdades psíquicas, esse conteúdo ainda se mantém estruturalmente único e idêntico frente ao fluxo de vivências psíquicas.

Pode-se também objetar, como atesta Husserl, que coexistência psíquica de representações ou juízos não são idênticas ou simplesmente equivalentes a compatibilidades ou adequação entre proposições e estados de coisas - portanto, a psicologia da evidência é irrelevante e até mesmo imprópria para explicar as relações lógicas em si. A primeira relação é uma conexão psicológica e só isso; a segunda é, com todo o direito, propriamente lógica. Em especial, esta crítica é dirigida às considerações de Alois Höffler (cf. HUSSERL, 1967a, p.212-213, §50, nota de rodapé 1).

O autor das Investigações não negligencia o papel prático e técnico da psicologia no estudo da evidência no decurso do pensar lógico e teórico; contudo, tal estudo deve se restringir às condições reais ou empíricas da evidência, claramente delimitadas pelo caráter indutivo das leis que as explicam. Em contrapartida, a evidência tem condições ideais que são determinadas por puras leis teoréticas apriorísticas, referentes a possibilidades e compatibilidades (ou o contrário) ideais.

Por conseguinte, é possível a existência de objetidades lógicas e matemáticas que não tenham evidência atual. Ausência de evidência não significa ausência de objetividade, mas o contrário é necessário - há aqui um paralelo com a constatação de que não perceber não significa não ser, mas o contrário é o caso. Logo, a evidência pode ser tomada como um ideal regulador de nossas cognições, mas nunca como um caráter de verdade, que é unicamente dado pela forma pura e pelo conteúdo significativo das proposições, regida por leis baseadas nestes caracteres ideais.

No §51, Husserl afirma veementemente a importância e o caráter fundamental da distinção, chamada por este autor de "epistemológica", entre o real e o ideal. Esta distinção, que é exaustiva e incontornável, deve ser entendida adequadamente, sob pena de prejuízo na compreensão da constituição e essência da 
lógica. Isto se dá, com efeito, quando se descreve e explica rigorosamente como no real o ideal "aparece", sob quais conexões e relações, quais as condições de sua cognoscibilidade, entre outros aspectos (HUSSERL, 1967a, p. 217, §51).

Apresenta Husserl, em continuação, um argumento de força persuasiva baseada em questões psicofisiológicas, a saber, de que seres humanos normais tem evidência de juízos verdadeiros enquanto um "sentimento" de intensidade, uma "força" que coage a aceitar um determinado enunciado como verdadeiro. Contudo, o autor atenta para o fato de que seres humanos normais podem fazer inferências incorretas ou não "sentir" evidência ao pensar em uma proposição ou inferência determinada (HUSSERL, 1967a, p. 218, §51).

Sendo assim, dada esta possibilidade real, a constituição normal psíquica humana não existiria factualmente, e, o que é mais plausível, o sentimento de evidência não é critério para atestar a verdade de uma proposição ou juízo, baseando-se em uma "força psíquica irresistível" para o assentimento.

Neste momento do parágrafo, Husserl elabora uma definição do que é a evidência, segundo as exigências e a conformidade com a lógica pura. Sendo assim, a evidência só pode ser entendida como vivência da adequação enquanto tal, entre um enunciado e a situação objetiva correspondente - a verdade enquanto ideia (HUSSERL, 1967a, p. 219, idem). Alude Husserl à diferença entre um juízo evidente e outro não evidente analogamente à diferença entre uma representação arbitrária de determinado objeto e uma representação adequada e plena. Portanto, a evidência é um caso real individual de uma estrutura ideal universalmente válida, mas ainda assim uma vivência com caráter objetivo. Por fim, esta definição tem por base a característica principal deste ato de doar originalmente a verdade, de ser acesso pleno à esta ideia pura de adequação como tal.

Logo, problemas de origem psicologista ou que supõem a teoria da evidência como "sentimento" perdem seu significado epistemológico, pois não tem sentido a pergunta: dada uma evidência de A, é possível outra evidência de não-A, ou de B, C e etc.? Se há doação originária de A em evidência, A foi apreendido de modo pleno, e sua objetividade não é menoscabada, pois dela depende qualquer juízo evidente. É a objetividade do conhecido que garante a correção do ato de conhecimento - Husserl também chama a evidência de "caráter do conhecimento como tal" (HUSSERL, 1967a, p. 220, idem).

Esta análise, ainda incompleta e provisória do conceito de evidência, e usada no contexto do postulado das "verdades em si" (segundo Husserl, mais adequado na refutação ao psicologismo e não em uma perspectiva essencialmente fenomenológica) (HEFFERNAN, 2014, p. 17 e cf. MILNAR, 2014, p. 39-40), 
já mostra o seu caráter triplo de justificação epistêmica, exigido para intelecções ${ }^{6}$ lógicas: trata-se de doação absoluta, adequada e apodítica. A primeira característica já foi elucidada, pois o conteúdo ideal a que remete este ato de conhecimento é nexo necessário que fundamenta a objetividade da evidência; as duas outras características estão presentes de modo ainda não estendido em toda a amplitude fenomenológica exigida, e é na Sexta investigação que isso será efetuado.

Na Sexta investigação, Husserl define evidência de modo com que sejam abarcados tanto o lado objetivo (o correlato intencional enquanto objeto presente em si, pleno e doado originalmente) quanto subjetivo (a estrutura essencial intencional, tanto em sua base material - sede do preenchimento - quanto no caráter posicional/qualitativo); ademais, vê Husserl a necessidade de se tomar o conceito de evidência de um modo lato e de um modo restrito, e, por fim, conforme a doação do objeto apreendido e a noção de verdade imbricada nesta doação.

Como definição geral dentro de todo o texto das Investigações, evidência é o modo de consciência que tanto constitui o objeto em toda sua completude objetiva e o apreende de maneira originária, quanto se designa por evidência a vivência da verdade, a ideia de adequação absoluta entre proposição e estado de coisas ou, do lado subjetivo, entre intenção de significação e preenchimento intuitivo ${ }^{7-}$ uma síntese definitiva de preenchimento, baseada na percepção pura adequada.

$\mathrm{Na}$ série de progressões de preenchimentos que caracteriza o progresso do conhecer - de um ponto de vista fenomenológico -, há momentos sintéticos em que cada vez mais "sombreamentos" ou perspectivas objetais são dadas por meio de percepções ou afigurações, em que sempre se há uma relação de ou alcance efetivo do próprio objeto ou uma decepção, por assim dizer, dentro desta dinâmica. Em outros termos, a presença ou semelhança do representado com o objeto vão se fazendo cada vez mais evoluídas e próximas.

Contudo, só percepções apresentam caracteres próprios, que o "apresentam" realmente, e não meramente conteúdos análogos ao objeto, como o faz a ima-

6"Intelecção" é a palavra usada por Husserl como sinônimo de "evidência apodítica" e isso em vários pontos das Investigações. Gaos e Morente, em uma nota de rodapé, distinguem os termos alemães Evidenz e Einsicht por considerações fenomenológicas. O primeiro termo expressa uma posição primária racional, ou evidência assertórica, e o segundo uma posição racional indubitável, ou evidência apodítica (HUSSERL, 1967a, p. 19, Prólogo, nota de rodapé 1). Entretanto, pode-se colocar duas objeções a esta caracterização: a distinção entre tipos de evidência nas Investigações é entre evidência em sentido lato (gradual, rumo à uma meta limite) e estrito (sínteses de adequação e confirmação definitivas); a palavra evidenz também é tomada em um sentido de adequação e apoditicidade definitivas (cf. HEFFERNAN, 2014, p. 6-7).

7 Intenção e preenchimento são dois momentos progressivos na vida intencional e são unificados quando há "síntese de adequação": o primeiro conceito designa a função "meramente simbólico-expressiva" da consciência enquanto possui uma referência objetiva significada; o segundo conceito expressa a apreensão plena e adequada à intenção da referência anteriormente simbolizada ou compreendida de modo não-intuitivo (cf. HUSSERL, 1967a, p. 330, §9). 
ginação. Logo, as sínteses de preenchimento se baseiam em percepções que, mesmo por meio de "escorços" e sombreamentos, alcançam a presença e a coincidência plena com o objeto.

Nota-se que, contudo - e é preciso dar relevância a isto -, a posicionalidade e a qualidade intencionais ainda não são levadas em conta, mas o caráter funcional de preenchimento, de completude intuitiva. Isto já foi mostrado na seção anterior, mesmo que sem uma relação tão próxima com o conceito de evidência. A importância dada por Husserl, até o §38, é na matéria intencional e no conteúdo intuitivo; nas percepções, este conteúdo é "presentado", tornado "presente ele mesmo, real" de maneira "própria" e não meramente analogizante ou por imagem, como já se disse acima. Entretanto, o caráter posicional da percepção não é levado em conta.

Há um ideal objetivo nessa progressão, que é o "isto-mesmo absoluto" do objeto e a percepção adequada deste, como correlato subjetivo. Logo, se produzem dois vieses nesta adequação e completude perceptiva: a adequação entre intenção e preenchimento e a adequação do preenchimento à completude do próprio objeto visado (cf. HUSSERL, 2001, p. 261, §37).

Chegado este momento descritivo, por assim dizer, são tematizados os caracteres essenciais qualitativos e posicionais, pois se muda a perspectiva e se ascende a um grau maior de "consciência" da síntese de preenchimentos: todo ato perceptivo é posicional, o que entra em consonância com a correlação entre existência e presença do objeto; toda identificação de progressão sintética dos preenchimentos é um ato posicionante, que se coaduna com a unidade de recobrimento perceptivo e se volta à própria verificação desse progresso na apresentação objetal e em sua futura confirmação. A relação entre adequação plenificada pelas sínteses definitivas de preenchimento e a síntese de confirmação, pois, é uma conexão de confirmação (HUSSERL, 2001, p. 263, §38).

Dois conceitos de evidência são apresentados no §38 das Investigações, posteriormente coadunados com a descrição fenomenológica da evidência em correlação com o conceito de verdade. Husserl chama de sentido lato de evidência quando há uma consciência posicional de preenchimento, em vários graus de recobrimento, rumo a uma meta limite; em contrapartida, há um conceito estrito, que se dá na síntese de verificação de preenchimentos definitiva, perfeita, adequada e apodítica (HUSSERL, 2001, p. 262-263, §38). ${ }^{8}$

8 É importante se fazer um adendo terminológico sobre o conceito de evidência, e isto com relação à tradução em língua inglesa das Investigações lógicas. Trata-se da pertinência do vocábulo self-evidence. Henry Pietersma e Georg Heffernan concordam que há um equívoco subjacente no termo, sendo que o sentido do termo inglês evidence ou seu correlato self-evidence não tem sentido equivalente a Evidenz (HEFFERNAN, 2014, p. 5 e PIETERSMA, 2000, p. 
Cabe enfatizar aqui que o conceito de evidência entendido como síntese cognitiva graduada supõe também decepções, mas possui uma meta limite absoluta, que serve como ideal normativo à crítica de todo o conhecimento em geral (HEFFERNAN, 2014, p. 18-19). Neste sentido, o telos que norteia a epistemologia da lógica de 1901 é a perfeição do conhecimento lógico, mas Husserl é consciente, diferentemente da tradição e da psicologia descritiva de seu tempo, de que a evidência só pode ser entendida de modo dinâmico.

Em seguida, no §39, quatro sentidos de evidência foram definidos e descritos, tanto em seu aspecto subjetivo quanto objetivo (HUSSERL, 1967b, p.445-446; HUSSERL, 2001, p. 263-364). A primeira acepção de "evidência" se refere à síntese de verificação e o ato objetivante que a constitui: aqui, a evidência desempenha o papel de síntese definitiva de identificação e, como estado de coisas identificado e correlato, temos a verdade enquanto adequação entre intenção e preenchimento. Neste caso, não se trata de mera percepção adequada da verdade, mas de uma consciência reflexiva desta identificação, que pode ser enunciada.

Por conseguinte, o segundo sentido é entendido enquanto ato empírico e instância da ideia de verdade. A ideia de "vivência da verdade" é a captação plena da ideia de adequação como tal, na multiplicidade de evidências individuais possíveis; este sentido de verdade se adequa, como já mostrado acima (p. 5), ao conceito dos Prolegômenos.

Da perspectiva "objetiva" a evidência é designada como perfeição de recobrimento: a evidência, aqui, é a adequação plena da intuição com os progressos sintéticos no constante "recobrimento" e aumento do grau de riqueza, extensão e realidade dos conteúdos intuitivos.

Por fim, tem-se uma perspectiva que incide na intenção de significação, a saber, enquanto correção da adequação: é a espécie de evidência do enunciado em si, da intenção enquanto "conforme" a uma intuição corroboradora.

Após estas definições, em continuação às descrições do §39, Husserl irá tratar de relações intrínsecas ao ato de evidência e ao conceito de verdade, distinguindo a evidência enquanto vivida e evidencia refletida e enunciada, atos relacionantes de não relacionantes e a conexão entre "verdadeiro" enquanto valor lógico e "ser", enquanto sentido objetivo e ontológico, por assim dizer, do ideal de adequação como tal.

182 , nota de rodapé 5). O segundo autor vê nessa ambiguidade e disparidade um entreve para o correto entendimento da dinâmica processual da evidência. 
Neste sentido, Husserl destaca a diferença entre a adequação expressa pelo "é" da cópula, indicando a concordância entre sujeito e predicado, e o "ser verdadeiro" apreendido em uma objetivação de grau superior. A primeira relação é vivida simplesmente, e serve de base para objetivações posteriores, construídas em sínteses de concordância. Estende-se aqui para outra distinção descritiva entre predicações e posicionamentos absolutos, entre adequações como concordância relacionante e não relacionante (HUSSERL, 2001, p. 265, §39). Deste modo, Husserl separa duas classes complementares da noção de verdade: enquanto ideia e enquanto doação do objeto plena e definitiva exposta em uma adequação entre intenção e preenchimento. Admite que, ao final, à noção de verdade, que corresponde à estrutura dos atos mesmos, é calcada nos atos relacionantes, enquanto que na noção de ser verdadeiro, o conceito de posicionamento absoluto e de não-estado de coisas (objetos enquanto tais) (HUSSERL, 2001, p. 266, idem).

Como complemento, é explicitado o caráter posicional do juízo, que entra em relação como conceito de verdade e não especificamente com o de ser verdadeiro. No entanto, o sentido estrito de evidência é tanto a síntese de preenchimento perfeita e definitiva, identificada e confirmada; o "juízo evidente", por assim dizer, é uma perspectiva de evidenciação e não, como as teorias tradicionais apregoam (em especial as empiristas), um complemento psíquico (HUSSERL, 2001, idem, ibidem).

Além disso, de modo breve, Husserl irá tematizar o ideal negativo limite de inevidência, isto é, a consciência de contrariedade absoluta, com os conceitos conexos de falsidade e não-ser, baseados em sínteses de "quase-preenchimento". Segundo o autor, é possível transladar os esquemas conceituais fenomenológicos da evidência para este conceito negativo (HUSSERL, 1967b, p. 449, $\S 39$ e HUSSERL, 2001, p. ibidem, ibidem.)

Ao final do parágrafo, que encerra também este capítulo, Husserl retoma uma parte importante da refutação de concepções empiristas ou psicologistas da evidência, aludindo ao caráter objetivo e ideal da verdade e o nexo válido entre evidência e verdade: se há evidência, sempre há verdade, pois houve uma apreensão originária e plena de uma adequação enquanto tal. Explica, na última frase, que a diferença entre o "ser" componente das relações de verdade é uma característica da matéria, que expressa concordância predicativa, e que o juízo (sempre um ato posicional) possui uma característica qualitativa e posicional, distinta da "mera representação" (HUSSERL, 2001, p. 267, idem e HUSSERL, 1967b, p. 450, idem). 


\section{A existência ideal das idealidades lógicas: a fenomenologia dos objetos ideais e categorias}

Em todas as Investigações, vê-se a necessidade teórica de se assumir a tese de que os objetos da lógica e das ciências formais possuem um modo de existência distinto do real (espaço-temporal). Afirma-se que os objetos da lógica pura são distintos de qualquer esfera da realidade, pois considerar os objetos desta ciência ou objetos psíquicos ou algo determinado de modo antropológico ou biológico compromete a objetividade e a validade de qualquer outra ciência: é a lógica que fornece a forma pura de toda a construção e conteúdo que faz toda e qualquer ciência ser ciência. Por fim, o caráter epistemológico da clarificação da lógica traz à luz a conclusão de que objetos reais e ideais são diferentes, apreendidos em modos de consciência próprios.

Por conseguinte, o conceito de existência ideal está vinculado ao intento de não só refutar o psicologismo na lógica, mas de compreender como estes objetos são apreendidos na consciência, e como essa apreensão pode ser justificada. Nos Prolegômenos, já é determinado o caráter apriórico, universal, necessário e válido dos conteúdos significativos das proposições, categorias e conceitos, além do próprio conceito de verdade.

A demonstração da existência ideal dos conceitos e proposições é construída com base em uma definição, em primeiro lugar, negativa, pois não são temporais nem especiais, nem determinados por algum tipo de conexão causal. Este objetos e categorias puras se referem unicamente à forma pura e ao conteúdo idêntico e unitário dos juízos pensados e proferidos, além de ser, como se disse acima, a estrutura a priori da ciência em si.

Na Primeira investigação, Husserl já concebe como elaborar uma descrição fenomenológica do modo de consciência em que apreendemos a idealidade do objetos lógico-matemáticos. Husserl, neste ponto do texto de 1901, mostra por duas vias complementares que as significações e objetos ideais são existentes em sentido próprio.

Em primeiro lugar, são "unidade na multiplicidade" pois, se, por meio de várias intenções de significação expressadas, visamos o mesmo conteúdo, e temos consciência compreensiva de que a expressões diferentes uma mesma significação as pode corresponder, então não é na multiplicidade de nossa vida psíquica e linguística que o objeto ideal possui consistência "ontológica" (cf. HUSSERL, 1967a, p. 386, §29). 
Em segundo lugar, são objetos em sentido próprio e não podem ser pensados de outra maneira, pois o correlato de uma intenção de significação não é uma ficção, mas um correlato que lhe é correspondente: há um conteúdo objetivo nos nossos enunciados ao qual corresponde uma objetividade ideal (cf. HUSSERL, 1967a, p.337, §11).

Logo, essa identidade de intenção é captada de modo intuitivo, e não pode ser construída; não constitui um caráter do ato significativo, mas tem como referência algo objetivo e independente desse mesmo ato. Por fim, afirmar que as significações são objetos que existem não significa afirmá-los como reais em uma outra esfera de ser, mas como existentes conceitualmente, independentes de qualquer constante ou categoria empírica (cf. HUSSERL, 1967a, p. 396, §31).

Tais conclusões só são possíveis com distinções claras e precisas nas vivências intencionais do que na escola de Brentano se convencionou chamar de conteúdo. Husserl, ao contrário de outros filósofos (Meinong, Twardowski), não define ontologicamente o que é o conteúdo intencional, mas delimita analítica e descritivamente qual é a função cognitiva do conteúdo intencional de uma vivência. Jocelyn Benoist vê tal diferenciação como essencial para ultrapassar as concepções de sentido e significado da escola de Brentano e dar um lugar devido ao tema da constituição das significações lógicas (BENOIST, 2001, p. 27).

A Segunda investigação apresenta a tese da existência ideal dos objetos lógicos justamente como necessária e essencial para uma correta compreensão das verdades lógicas (HUSSERL, 1967a, p. 407-408). Tudo aquilo que proposições verdadeiras tomam como existente não pode ser fictício ou falso: em primeiro lugar, porque não existem objetos "falsos" - ou existem, ou não existem - e, em segundo lugar, porque os objetos ideais não são objetos "impróprios" ou ficcionais: não se trata de existência suposta, mas de existência afirmada conceitualmente. Se uma proposição toma que objetos gerais ou específicos (gêneros e espécies) existem, e essa proposição é verdadeira, esse objeto deve corresponder a essa proposição, e sua intenção de significação também visa esse tipo de objetidade de maneira genuína em um ato que a doe de maneira completa e adequada (HUSSERL 1967a, p. 422, §8).

Todas estas diferenciações e identificações objetivas e essenciais são garantidas por evidência; é garantido por evidência, além disso, que há preenchimentos e determinações intuitivas próprias para a apreensão das unidades objetivas lógicas (HUSSERL, 1967a, p. 405, §1 e cf. BENOIST, 2001, p. 84).

Ao longo de toda a Segunda investigação, há a necessidade de refutar as teses contrárias, especialmente as concepções empiristas de significado e con- 
ceito. O fato de que tanto esse tipo de objeto pode ser captado em intuições específicas, e que tais intuições podem ser verificadas e distinguidas por evidências, por conseguinte, mostra que epistemologicamente podemos sustentar a existência e constituição específica de objetos ideais.

Na Sexta investigação, em continuação à esta defesa do realismo lógico, o desdobramento deste tema se completa, pois Husserl desenvolve uma teoria da intuição que seja capaz de compreender como da nossa vida psíquica real podem se "originar" o sentido expressivo e como esse mesmo sentido se corresponde com a apreensão dos objetos em si mesmos, e como essas coincidências e correspondências vão progressivamente ampliando o conhecimento.

Em contrapartida, as intuições desempenham funções de preenchimentos e doação objetivas que não podem ser restritas aos objetos sensíveis: nem todo sentido linguístico visa uma percepção ou imaginação que tem como correlato um objeto sensível, mas também categorias, conectivos, cópulas, operadores lógicos etc. (HUSSERL, 2001, p. 279-280, §43-44).

Por desempenhar as mesmas funções cognitivas e visarem objetos de outra ordem, não é inconsistente chamar o ato psíquico respectivo de "intuição", e intuição de objetos "não sensíveis". Contudo, não se trata de objetos reais em outra esfera de mundo, ou coisas em si, ou caracteres formais das coisas existentes no nosso mundo, muito menos formas puras de nossas percepções internas, mas objetos "de ordem superior", "complexos". Trata-se de categorias e formas categoriais. Logo, a intuição é chamada de categorial, que não simples ou "unirradial", de um único sentido objetivo, mas uma matéria intencional "fundada" em percepções ou imaginações "fundantes" (HUSSERL, 1967b, p. $478, \S 48)$, unidas em uma síntese categorial visando um objeto categorial (HUSSERL,1967b, p. 480, §49).

Os atos intuitivos categoriais têm como correlatos tanto as formas gramaticais referentes à estrutura de enunciados empíricos quanto os puros (cf. HUSSERL, 1967b, p. 460-461, §43). A diferença essencial entre estes dois tipos de atos está em sua fundação: na primeira classe, as intuições sensíveis fundantes não variam de modo livre, ao passo que, na segunda classe, a fundação sensível pode variar infinitamente. Veja-se, por exemplo, o enunciado "este quadro é verde", já que a cópula é uma forma categorial e gramatical pura, mas os conceitos "quadro" e "verde" não possuem, neste caso, objetos ideais visados; por outro lado, veja-se o exemplo de enunciados como "a é parte de A e A é um todo referente à a" (cf. HUSSERL, 1967b, p. 476, §48). 
Husserl, descrevendo a estrutura dos atos categoriais, assim como o modo de preenchimento próprio a estes, salienta que a formação de seus conteúdos intuitivos se dá na reflexão - não na apreensão de formas "internas" obtidas por reflexão -, que são sintetizados e unidos com fundamento na matéria intencional dos atos intuitivos simples e empíricos. Novamente, em funções de preenchimento, não é a qualidade e o posicionamento que entram em jogo; contudo, a qualidade intencional (percepção, imaginação) entram na dinâmica da adequação e no progresso das sínteses de preenchimentos rumo à evidência.

Há, por fim, a confirmação definitiva e, como descrito anteriormente, as perfeições próprias ao conhecimento em si. Neste âmbito, entra em jogo a problematização do conceito de síntese identificadora e, em paralelo com a unidade de identificação objetal específica, aludida acima na delimitação do conceito de evidência, que é relevante em todo o progresso rumo à evidência e na própria constituição deste tipo de objetidade (cf. HUSSERL, 1967b, p. 500-501, §57).

\section{A relação entre existência ideal e posição de existência: limitações e problemáticas}

Nesta seção, serão levantados os problemas presentes tanto na definição de existência enquanto ideal e a priori e o conceito de existência enquanto posicionamento para, por fim, como as sínteses de preenchimentos ideatórios e categoriais podem demandar uma análise mais minuciosa da constituição do caráter posicional dos atos de evidência. É preciso elucidar e reconstruir os nexos teóricos e argumentativos que Husserl usa para inscrever em um progresso dinâmico todo o processo de conhecimento referente aos objetos ideais.

Cabe relembrar que a consciência, como já foi analisado na seção III, tem como característica essencial, em cada vivência dos mais variados tipos de objeto, visar esse dado objetivo afirmando, negando ou deixando em suspenso sua existência. Contudo, não é esse tipo de caráter de ato que afere o atributo “existência” para uma significação ou para qualquer tipo de objeto, o que já foi abordado anteriormente. A relação entre caracteres posicionais e a idealidade visada é de natureza cognitiva: o objeto é vivido em um modo determinado de crença e direção objetiva.

Entretanto, vê-se que a posição de existência e a existência ideal são, no sentido epistemológico, correlacionados e que nenhuma divisão exaustiva pode anular essa constatação. Contudo, a relação em si não é plenamente exposta em 
total claridade, principalmente por alguns problemas que podem ser mostrados, a saber, os que são pertinentes às próprias estruturações das vivências intencionais e às funções cognitivas.

De modo mais específico à epistemologia das Investigações, a análise dos caracteres posicionais é relevante pela constatação que identificações, diferenciações e a as sínteses de que são constituintes dependem de posicionamentos - a possibilidade ou impossibilidade cognitiva determinadas pela matéria intencional adquirem uma dimensão dinâmica e progressiva com esta estruturação, determinada pelo conceito de confirmação: "O conceito de confirmação se refere exclusivamente ao atos posicionais em relação ao seu preenchimento e, em último termo, ao seu preenchimento por meio de percepções" (HUSSERL, 1967b, p. 444, §38).

Os modos de intuição ideatórios e categoriais também visam seu objeto de modo a tomá-lo como existente; a diferença intrínseca é o modo de constituição efetuada por este ato e sua referência objetiva; contudo, se por um lado a matéria fundamenta a possibilidade de realização intuitiva, e a qualidade a confirmação e verificação desta, uma teoria da evidenciação categorial tem que problematizar sua estrutura intencional. Husserl, como veremos, traz complicações importantes a partir deste ponto.

Neste sentido, o caráter qualitativo e posicional das vivências psíquicas é muito problemático no âmbito do processo de conhecer. Diferenciações classificatórias, assim como definições importantes no que se refere à constituição por meio de unificabilidade e identidade são pouco precisas e alguns nexos tanto intencionais quanto ideais foram escamoteados. Isso compromete uma apreciação fenomenológica consistente do conceito de evidência. Mais: prejudica a fenomenologia da constituição da evidência das objetidades lógicas, que são coordenadas por sínteses. Trabalha-se com paralelos (ideal/real, objetivo/subjetivo, sensível/categorial e etc.) sem que se construa um nexo estrutural definido.

É importante o leitor notar, por conseguinte, como uma estruturação correta do caráter existencial dada no posicionamento é muito importante para o caso específico da evidência categorial, já que, como se mostra no $§ 39$, do juízo verdadeiro há sempre uma conexão ideal com o estado de coisas verdadeiro. Lidamos, de modo correlacional, com conceitos lógicos e epistemológicos essenciais.

Ivana Milnar afirma que, nas Investigações, o caráter modal (possibilidades e impossibilidades de realização objetiva de uma menção simbólica ou vazia) da evidência reside na matéria intencional enquanto possibilidades puras de preenchimento; é na função de preenchimento que reside toda a especificidade da evidência 
nas Investigações Lógicas e, em especial, é na matéria intencional que reside o fundamento no qual se efetuam as sínteses de preenchimento (cf. MILNAR, 2013, p. 46-47). Contudo, não seria a síntese também um ato posicionante, já que as identificações e diferenciações no progresso de "recobrimento" e "recheio" não são propriedades materiais, mas também qualitativas? A base e definição de conhecimento, em sentido estrito, significa síntese definitiva de preenchimento.

Ströker, em Husserl's principle of evidence: the significance and limitations of a methodological norm of phenomenology as a science (1997), afirma que a intuição categorial e a evidência correspondente a esta não são totalmente claros e precisos, principalmente nas conexões entre formas categoriais, preenchimento efetuado por intuição categorial e o caráter de síntese de união e identificação presentes neste ato (STRÖKER, 1997, p. 68-69). Afirma, igualmente, que a divisão entre intenções e preenchimentos categoriais é questionável, assim como o modo de recobrimento contínuo da apreensão de categorias, fundado na união das matérias fundantes em uma única matéria fundada. Que papeis desempenham a confirmação e verificação próprias da evidência atual neste complexo progresso de completude intuitiva?

Nota-se outro problema, apontado por Robin Rollinger no ensaio Names, statements, and their corresponding acts in Husserl's Logical Investigations, a saber, que Husserl toma a posicionalidade em estreito paralelo com a linguagem e, por isso, torna-se partidário de uma injustificada correspondência entre os tipos de caracteres de atos e os tipos de expressões. Translada, igualmente, este paralelismo para a idealidade das categorias, como os estados de coisas, assim como para as sínteses de preenchimento.

Levar-se-á em conta, neste estudo, a problematização que Rollinger faz acerca da diferenciação e classificação dos atos nominais e proposicionais. Questiona, em primeira instância, a pertinência de uma classificação entre "nomes posicionais" e "nomes não posicionais". Em segunda instância, pergunta se realmente é uma diferença real a caracterização de posicionamento proposicional multirradial, isto é, o assentimento de crença na existência de um estado de coisas é diferente dessa mesma crença em uma expressão nominal (cf. ROLLINGER, 2003, p. 139-140, .3).

Além disso, há novamente a questão de que a distinção entre "mera representação" e "juízo", ou seja, termos qualitativos, precisa de uma fundamentação mais robusta. Logo, as implicações desta falta de rigor influenciam na compreensão do que seja o juízo, em especial, quando correlacionado de modo evidente, com um estado de coisas. Rollinger assevera que estas dificuldades 
surgem com uma pouco cuidadosa abordagem das vivências psíquicas simbólicas por parâmetros linguísticos tradicionais, como a estruturação tradicional do juízo (sujeito-cópula-predicado) (cf. ROLLINGER, 2003, p. 141, idem).

Isso se aplica de modo mais preocupante ao conceito de estado de coisas, a saber, categorial. Rollinger esposa a objeção que, nas sínteses de preenchimento e no próprio preencher categorial, não foi posta uma diferença entre um evento (empírico, real) e um estado de coisas (lógico, ideal). Um exemplo desse problema é a classificação da proposição "este papel é branco" ou "este melro é preto" como a expressão de um evento visual ou do estado de coisas estruturado pela cópula. É claro que Husserl enfrenta objeções deste tipo, quando trata da diferença entre formas empíricas e formas categoriais; contudo, a objeção é centralizada no caráter que diferencia uma percepção sensível da categorial. Trata-se de uma objeção voltada ao preenchimento e não diretamente ao posicionamento e à confirmação.

Contudo, é possível verificar inconsistências no modelo fundacional de Husserl com referência à epistemologia dos atos categoriais, que se confunde com um "modelo de fundação ontológica". Aqui, como é problematizado por Thomas Nenon (ainda que por outras áreas mais amplas do que o domínio lógico), Husserl aceita, por um lado, que o modelo de fundação por relações de dependência pode ser estendido para a investigação fenomenológica como um todo, mas, no caso da intuição categorial, este modelo é distinguido de modo precário.

A despeito desta consideração, é preciso ressaltar que não se irá discutir de modo aprofundado questões mereológicas ou de ontologia formal (no sentido empregado nas Investigações), mas enquanto forem necessários para se discutir aspectos ontológicos problemáticos.

Enquanto que as relações de dependência ontológica dão primazia fundacional ao simples/independente/concreto frente ao complexo/dependente/abstrato (NENON, 1997, p. 103), na Sexta investigação as relações de dependência se tornam mais ambíguas. No modelo ontológico, o todo tem primazia sobre as partes - um todo determinado é independente e concreto, ou seja, existe "em sentido próprio" -, porque estas são dependentes/abstratas; no modelo epistemológico, se as intuições categoriais (um todo) são fundadas em percepções sensíveis (partes) unificadas sinteticamente - as partes tem primazia fundacional sobre o todo. Contudo, pergunta-se: como Husserl pode sustentar que as categorias têm primazia fundacional ontológica, mas não epistemológica (cf. NENON, 1997, p. 110)?

Esta crítica ganha uma importância fundamental, pois coloca em questão as conexões entre caracteres ontológicos e objetivos, por um lado, e aspectos epistemológicos e subjetivos, por outro. É preciso lembrar que, na caracterização da 
estrutura essencial dos atos psíquicos, a essência intencional é fundante e concreta, sendo que qualidade e matéria intencionais são momentos abstratos das vivências. Em contrapartida, questiona-se qual é o modo de fundação das categorias é baseado nas matérias dos atos fundantes e em seus correlatos objetivos "simples".

Nenon, todavia, não leva em consideração os modos de sínteses unificadoras que entram em jogo no modelo epistemológico de fundação, diversos de uma síntese empírica. Husserl, neste caso, é procedente ao dar ênfase neste aspecto, embora recaia em outros equívocos, como o problema classificativo referente à qualidade/posicionamento dos atos (aludido supra) e não daria um critério diferenciador claro entre síntese empírica e não empírica - e esta, por sua vez, seria essencial ao caráter próprio da evidência e preenchimento dos objetos ideais e categoriais

Logo, a "posição de existência" é um caráter de ato que merece uma preocupação mais precisa. Relacionar a possibilidade de preenchimento, fundada na matéria, com a confirmação e síntese de identificação e, em consequência, que determinada objetividade foi dada e dada realmente, fazem questionar se é possível, como forma de concatenação destes problemas, uma abordagem do paralelo entre existência ideal e existência enquanto posição. A fenomenologia de 1900-1901 pode subsidiar tal perspectiva?

Percebe-se que há uma "qualificação" do ato de evidência que é primordial para o correto entendimento deste conceito (cf. STRÖKER, 2001, p. 51), e isto não é diferente, dadas as análises até aqui feitas, para a evidência dos modos de doação categorial e ideatória.

Para responder esta questão, será feita uma síntese dos problemas até aqui encontrados, além de um enfrentamento, que visa mostrar uma possível saída para relacionar, na dinâmica do conhecimento, caracteres de ato e a estruturação dos objetos ideais e categorias.

\section{As implicações epistemológicas e limites da evidenciação e conhecimento da esfera lógica: análise dos problemas e possíveis enfrentamentos nas Investigações lógicas}

Os problemas referentes aos conceitos tratados acima e os desdobramentos conceituais respectivos serão, nesta seção, tratados de modo acentuado, mesmo que retrospectivo. No entanto, este momento do artigo tem como objetivo abordar questões pertinentes aos limites conceituais de Husserl, além de como nossa 
hipótese se encaixa na solução e na interpretação dos problemas que, progressiva e analiticamente, foram sendo clarificados ao longo de outras seções. Trata-se, com efeito, de direcionar as análises anteriormente feitas para a resolução do problema da conexão entre existência ideal e posicionamento.

Contudo, vê-se que os problemas aqui mostrados poderão ser resolvidos de uma forma coerente se se atentar ao enfrentamento dos seguintes pontos, construídos sobre as bases das análises anteriores:

a) A relação entre ideal e real, assim como as relações entre instância e espécie, multiplicidade e unidade/identidade. Reconsidere-se, aqui, a divisão exaustiva entre a esfera real e ideal do conhecimento. Husserl analisa e constrói uma epistemologia baseada nesta distinção e como elaborar uma correlação sem haver a assunção ao psicologismo ou a um realismo sem contato com a esfera real.

Entretanto, isso não significa que entender a evidência como uma instancia da ideia de verdade e, portanto, como dependente da idealidade "em si", não seja questionável. Husserl argumenta que a validade ideal da verdade condiciona a justificação por meio de evidência - e tal afirmação é robustecida com a refutação de uma teoria empirista da evidência; porém, como conciliar esta versão deste conceito estritamente ligada às idealidades com uma concepção gradual de evidenciação?

Como vimos anteriormente, o pressuposto da primeira definição de evidência é a refutação do psicologismo lógico, e, por isso, só podemos entender a evidência em relação com a Sexta investigação, ou seja, a evidência enquanto vivência real da verdade ideal com a evidência enquanto modo de consciência de doação originária da verdade e dos objetos.

Há o postulado problemático das "verdades em si", como foi mostrado acima, que torna a evidência um conceito referente a casos empíricos da verdade, e somente isso; entretanto, enfatizando o progresso dentro das Investigações a respeito do conceito de evidência, vê-se que sua perfectibilidade, que não se reduz à conexão ideal com a verdade enquanto ideia, mas ao caráter "objetivante" e originário da doação evidente, enfrenta a dificuldade de entender as possíveis decepções cognitivas e a possibilidade de "evidências" graduais.

Contudo, Husserl busca conectar a esfera real e ideal na Sexta investigação, através do conceito de evidência enquanto doação originária e conhecimento como síntese progressiva dinâmica de preenchimentos; as intuições categoriais entram neste processo epistemológico, que não só ampliam o alcance da conexão lógica entre espécie e instância, mas a complementam no constituir esta 
mesma objetividade como fundada nas intuições sensíveis e com estrutura correlacional (veja-se o capítulo VII da Sexta investigação).

Husserl não desenvolve, como se pode mostrar, apenas a noção espécie-instância como modelo epistemológico e lógico de conexão entre real e ideal, mas amplia, já nas Investigações, modelos correlacionais ou construídos em sínteses constitutivas. Entenda-se, nos $\S \S 11,29$ e 31 da Primeira investigação, além do capítulo VI da Sexta investigação, uma tensão entre dois modelos de "realismo" lógico e semântico, não redutíveis um ao outro.

b) Os problemas referentes à definições e funções cognitivas dos caracteres de ato, principalmente na estrutura da evidência. Constata-se que a matéria intencional serve tanto como instância quanto fundamento cognitivo em qualquer função de síntese impletiva; preenchimento e identificação também estão estruturados em um mesmo contexto, enquanto possibilidade ou impossibilidade de realização intuitiva pura de um conteúdo lógico. Entretanto, modificações qualitativas realmente não são pertinentes nestas sínteses? Recordemos uma diferenciação fundamental destes caracteres intencionais no ato de evidência, que é entre o "ser ou não ser" determinados pela matéria e, como já foi definido acima, a diferenciação entre "mera representação" e juízo.

Na evidência, o caráter posicional adquire importância, mas não uma definição precisa. Conceitos como "confirmação" e "verificação" necessitam de uma estrutura essencial mais bem definida qualitativa e posicionalmente. Todavia, é preciso verificar se a noção de juízo enquanto posicionamento não permite uma melhor definição deste caráter de ato.

Husserl, como foi mostrado acima, assevera que, na evidência, "posicionamento concorda com posicionamento". O conceito de "juízo verdadeiro", “evidente", embora coadune mais com a afirmação de muitos equívocos já explicitados, é acentuadamente posicional. Há uma dinâmica de concordâncias descrita que abrange de modo mais completo a noção de existência, neste caso relacionada com um estado de coisas. Entretanto, se, do polo subjetivo, é possível nos voltarmos para o caráter posicional, no polo objetivo o paralelo comporta problemas graves.

c) Dificuldades referentes aos caracteres de ato das abstrações ideatórias e intuições categoriais, assim como a função cognitiva correspondente de cada um. Há uma importância secundária e não definida do caráter posi- 
cional, dentro da construção dos atos de ideação e da intuição das categorias e estados de coisas, sendo que em toda a síntese de verificação e identificação há um caráter qualitativo/posicional e não somente material? Por fim, existência e identificação se entrelaçam e se coimplicam na constituição do ato de evidência; em que sentido há a constituição das sínteses categoriais por este meio?

Após todo o itinerário construído até aqui, não se pode esquivar deste problema, se quisermos dar um papel significativo ao conceito de posição de existência efetuado em caráter de ato. Vê-se que fica impossibilitada, por essa via, uma relação cognitiva que compreenda a objetividade ideal, dado que uma percepção, que tem um caráter qualitativo e posicional definido, tem primazia na dinâmica da evidência.

Pode-se levantar, e por motivo justo, que há uma diferença entre a "existência" enquanto posicionamento e "presença", que é uma característica impletiva e, portanto, fundada materialmente. Husserl dá primazia à segunda, isto é, como intuitivações alcançam um grau de apreensão do objeto enquanto presente em si. Contudo, a percepção contém o caráter de "existência" e este caráter é levado em conta nas sínteses de confirmação.

d) As limitações da conexão entre o caráter qualitativo e posicional e o conceito de síntese de identificação categorial. Há, como já foi analisado em vários pontos deste artigo, uma problemática relação entre caráter qualitativo e posicional, além da referência à função de caráter de ato reservada para a posicionalidade e para a qualidade intencional. Há um papel importante a ser desempenhado nas sínteses categoriais e ideatórias e, contudo, vê-se que este papel não é determinado.

Novamente, Husserl não desconsidera o caráter posicional nas sínteses categoriais, mas releva a questão de como a evidência da apreensão de objetos categoriais necessita deste esclarecimento. Pode parecer que este problema é derivado do anterior, mas não é possível somente verificar a equivocidade da estruturação dos caracteres de ato, mas é igualmente possível mostrar igualmente que a defesa de um realismo lógico centrado em uma noção de "existência" diferenciada precisa de um correlato subjetivo, a saber, a afirmação "como existente" do intuir categorial - especificamente, da percepção categorial.

Pode-se indagar que a imaginação categorial, assim como uma percepção categorial, pode constituir objetividades de ordem superior, porque o preenchimento intuitivo tem base na matéria intencional. Entretanto, a síntese identificadora que 
é própria a esses atos, assim como à evidência possível, não encontram apenas na matéria intencional seu fundamento. Neste sentido, parece faltar ao capítulo VI da Sexta investigação uma descrição da evidência própria a categorias, como complemento e fecho à descrição do §39 (cf. HUSSERL, 1967, p. 476, §48).

Nota-se, neste caso, que a sustentação da tese sobre a existência ideal das categorias enfrenta, como exposto no item anterior, um outro obstáculo: se em c), o problema estava na dificuldade em estabelecer a estrutura do próprio ato, aqui aparece o problema da dinâmica que é sustentada por essa estrutura intencional. Se admitíssemos a possibilidade de um conceito mais definido de posicionalidade para as Investigações, ainda restaria uma limitação na concepção de síntese, cujo caráter categorial não é explicitado em detrimento das sínteses de identificação sensíveis.

Entretanto, é o conceito de síntese de identificação que caracteriza qualquer tipo de evidência como "confirmadora". Logo, uma síntese categorial é constituída de modo justificado por sínteses paulatinas de identificação. Aqui, vê-se que não é necessário que haja uma fundação posicional (isso é mostrado na dinâmica da evidência), o que pode fornecer uma possibilidade de conciliar a constituição de categorias por união das matérias intencionais dos atos fundantes. Aqui, não se olvida o caráter de síntese de preenchimento, que fundamenta a possibilidade de adequação, mas é preciso este complemento que, no caso, é distinto de certa forma de um caráter qualitativo.

\section{e) Os problemas referentes à estruturação dos correlatos objetivos em}

si. É preciso enfatizar que não se trata, neste momento, de uma recapitulação do problema da relação entre esfera real e ideal, mas da estrutura ideal enquanto correlato objetivo. A possibilidade da relação já foi problematizada; neste momento, portanto, volta-se à reflexão para o "objetivo" das vivências, da relação considerada em seu polo objetivo.

Vê-se que estes paralelismos são problemáticos, e envolvem tanto as questões próprias dos progressos no preenchimento quanto no caráter de ato (proposicional e nominal). Nota-se, com efeito, que o paralelo entre sínteses categoriais e intencionais, e a fundamentação destas pelas sínteses de adequação e preenchimento, comporta alguns limites constitucionais, assim como o caráter sintético identificador e unificador ser problemático, isto é, requerer uma forma de preenchimento e confirmação complexos e constantes. 
Além disso, o modelo fundacional de Husserl aplicado aos objetos lógicos e categorias é problemático, e não sem embaraços a fenomenologia de 19001901 pretende clarificar constitutivamente esta conexão ideal de fundação nos conceitos de síntese e de unificabilidade, que também são problemáticos, como foi mostrado acima. Vê-se que, ademais, eles possuem um caráter concreto e independente, se ontologicamente considerados. É suficiente, para resolver uma clarificação mais acentuada do caráter posicional dos atos categoriais e suas evidências correlatas? A resposta não é, certamente, uma hipótese neste sentido exclusivo, mas uma proposta que conecte caracteres estruturais objetivos.

Trazendo os questionamentos para um problema contextual, como verificar uma possibilidade de solução dentro do contexto das Investigações? Seria possível, ainda, uma solução baseada na lógica interna deste texto?

Os problemas levantados em b), c) e e) mostram uma carência conceitual e teórica nas Investigações, que seu próprio autor notou, com relação a alguns percalços. Entretanto, os problemas levantados em a) e d) oferecem a possibilidade de articular o caráter posicional e a idealidade em si de uma maneira coesa.

Considere-se, após todos estes enfrentamentos, uma possibilidade de solução. Pode-se conectar à relação entre ato categorial-estado de coisas, um conceito preciso de correlato objetivo empírico base, pré-categorial e pré-judicativa (que não é um caso real de uma espécie), que não seja categorial, mas possua uma primazia "semântica", de determinação do conteúdo significativo das proposições e categorias. Tal conceito é o de "situação de coisas (Sachlage)" e a concepção de intuição categorial parece exigir isto - semântica e ontologicamente, estas três instâncias parecem fornecer uma explicação basilar consistente para definir "existência ideal". Esta é uma das teses de Guilhermo Rosado Haddock (HADDOCK, 2000, p. 254).

Entretanto, tal conceito tem matizes características de uma concepção genética de intencionalidade e constituição, que não estão presentes nas Investigações. Haddock afirma, ao contrário, que o mesmo já está presente, ainda que com distinções incipientes, na Seção II da Sexta investigação, precisamente no $\S 48$ (cf. HADDOCK, 2000, p. 256 e HADDOCK, 2010, p. 36).

Além disso, essa concepção de "pré-categorial" supõe uma compreensão das instâncias "pré-judicativas" de constituição intencional. Neste caso, não está ainda presente uma consideração deste tipo no contexto de 1900-1901. Por fim, como, na progressão dinâmica da evidência, as instâncias semânticas significado-estado de coisas-situação de coisas entram em jogo? Este não é o interesse de Haddock ao mostrar a pertinência e vantagens teóricas destes conceitos e suas relações, mas, neste estudo, uma possibilidade de solução dos problemas aludidos acima não pode ser consistentemente sustentada por esse viés. 
Na próxima seção, apresentar-se-á uma intepretação que, considerando os principais estratos de constituição intencional e estruturação objetiva-ideal das Investigações - além de centrada em seu contexto próprio -, pode proporcionar uma alternativa de resolução dos problemas classificatórios e constitutivos das Investigações na fenomenologia dos objetos e categorias lógicas.

\section{A possibilidade de uma reestruturação entre a teoria do juízo, os conceitos de síntese identificante e de estados de coisas}

Husserl deixou sugestões descritivas que permitem uma ampla reconsideração modal da constituição da evidência aplicada às idealidades, que permitem uma recomposição dos conceitos já mostrados acima como problemáticos. Em primeiro lugar, a constituição, deixada em aberto, de uma teoria do juízo - ausente de claras e completas considerações posicionais/qualitativas. Em segundo lugar, a delimitação das sínteses de confirmação e identificação no processo de evidência categoriais. Finalmente, em terceiro lugar, uma delimitação mais rigorosa do conceito de estado de coisas.

A teoria do juízo exposta nas Quinta e Sexta investigações merece especial atenção na evidência e conhecimento das objetidades ideais. Este aspecto foi explicitado, ao longo do texto, como um nível justificacional necessário para este tipo especial de evidência. Hardy, em seu livro Nature's suit: Husserl's phenomenological philosophy and the physical sciences (2013) compreende que a justificação - e isso em corroboração com o caminho proposto aqui - , neste caso, é a garantia da aceitação de que determinado objeto ou estado de coisas foi doado "em si", adequando esta justificação a uma concepção graduada de "evidenciações" e que tem um ideal limite (cf. HARDY, 2013, p. 85).

Contudo, não se trata de menoscabar a síntese de preenchimentos como "secundária" em relação à síntese de posicionamento - o que seria uma artificialidade com o texto husserliano -, mas identificar a carência de uma teoria do juízo categorial baseada nos posicionamentos que seja clara e consistente, pois o caráter sintético fundado que é constituição peculiar dos atos categoriais obteria seu nexo justificativo (uma confirmação) em relação com os preenchimentos, representando, assim, um grau superior de definitude e apoditicidade necessários para as evidências lógicas 9 .

9 Aqui, não se quer dizer apoditicidade e perfeição exclusivamente por caracteres qualitativos e posicionais - a objetividade não é transferida artificialmente da esfera subjetiva para a objetiva -, mas unicamente ressaltar que o progresso do conhecimento, em especial o categorial, necessita destes aspectos, mais clarificados e conectados com aportes materiais intencionais. 
Husserl deixa em aberto a possibilidade de uma teoria do juízo categorial em complemento à teoria do preenchimento em intuições desta classe, além de ser condição suposta para estender o conceito de "intuição", dado que se abre a possibilidade de visar o caráter posicionante e não presentante das intuições para a síntese categorial.

Sabendo-se que a relação entre real e ideal pode ser compreendida e explicada de modo correlacional e, ainda, que a síntese de identificação enquanto posicional não oferece uma lacuna para se apropriar indevidamente da relação qualidade/posicionalidade, então podemos explicitar uma série de complementações que Husserl deixou pouco clarificadas - o complemento entre "possibilidade" e “identificação" (veja-se em MILNAR, 2013, p. 54, como há uma sobreposição e equívocos de Husserl referentes a "síntese de preenchimento" e "confirmação").

Partindo-se deste ponto, deve-se conectar de forma mais robusta e clarificada as formas de sínteses de preenchimento às de sínteses de identificação. Se é na matéria que reside o preenchimento e a presentação originária, é no processo sintético identificador que esta é legitimada. E, portanto, sendo uma idealidade tornada realizável intuitivamente, esta realização precisa de uma definição confirmadora, levando em conta a perfeição que é exigida da evidência e do conhecimento em geral nas Investigações.

Todavia, em que sentido - e este parece ser um problema mais intrincado - se pode considerar uma reestruturação do conceito de estado de coisas? Verificou-se que o conceito de "situação de coisas", nas Investigações, é insuficiente e muito vago para uma consideração mais apropriadas das relações entre objetos lógico-semânticos e as vivências na dinâmica da verdade.

Já enfrentadas as objeções referentes à questão da distinção entre "evento" e "estado de coisas", como foi elucidado acima, dado que esta não é uma mera diferença descritiva de um fenômeno, mas de objetos, deve-se novamente mencionar que uma teoria equívoca de sínteses de identificação não fornecerá suporte descritivo fenomenológico para a apreensão deste tipo de idealidade (cf. HUSSERL, 1967b, p. 454, §40). Além disso, a questão da fundação de caráter ontológico, que está turvada por problemas no modelo fundacional epistemológico, não permite entrever uma saída para esta limitação. Isto se dá pela razão de que é preciso uma reestruturação do conceito de síntese de identificação para que o constituir de um estado de coisas seja descritivamente coerente. 


\section{Considerações finais}

Deve-se reconhecer, após todo o itinerário das Investigações, a limitação desta obra não só na consideração do que constituem os caracteres essenciais dos atos psíquicos, mas como esta estrutura essencial serve de base descritiva na dinâmica do conhecimento. Ainda que, de modo consistente, Husserl desenvolva com clareza e correção os caracteres descritivos dos progressos no preenchimento, deixar em um plano secundário os caracteres de posicionalidade não permitiu a Husserl uma construção de uma epistemologia dos objetos categoriais que consiga fundamentar a tese da existência ideal dos objetos lógicos sem margem a objeções consideráveis.

O estudo, em decorrência destes problemas, mostra que uma possibilidade de se reconsiderar uma epistemologia das idealidades passa pela tematização dos conceitos de "confirmação" e síntese de identificação e unificação; dada esta primeira tematização, o segundo estrato descritivo seria a reflexão sobre os caracteres de atos judicativos categoriais para, por fim, colocar adequadamente o problema da constituição dos objetos de ordem superior com um tipo peculiar de síntese.

Constata-se a insuficiência de se pensar uma modalização das vivências intencionais, necessárias à lógica. Trata-se, no entanto, do fato de que Husserl tem como objetivo uma descrição dos atos de plenificação intuitiva e realização objetiva, e não estritamente dos caracteres téticos (usando um termo externo às Investigações) da consciência. No entanto, como os atos judicativos exigem uma problematização da qualidade intencional, não há como se contornar a pertinência epistemológica de um modo coeso de conexão entre doação e confirmação.

Por fim, deixa-se aberto se somente durante o progresso da produção textual de Husserl é que se entrevê uma solução para os problemas tematizados em 19001901. Os objetivos deste artigo foram alcançados com a constatação de que uma explicitação consistente e adequada do problema da existência ideal, dentro da lógica interna das Investigações, deve conectar de modo mais claro possível caracteres descritivos e epistemológicos - precedida por uma clarificação dos mesmos -, antes de se perguntar pela pertinência dos argumentos usados tanto para refutar teses contrárias quanto para afirmar o reino da lógica como um reino de objetos em sentido próprio; isto não acontece nas Investigações: os conceitos de "síntese" e os correlatos "síntese identificante" e a relação entre verificação e confirmação são as bases para um tratamento mais rigoroso deste problema. 
BENOIST, J. Intentionalité et langage dans les recherches logiques de Husserl. Paris: Presses Universitaires de France, 2001.

HADDOCK, G. E. R. On the Husserl distinction between State of Affairs (Sachverhalt) and Situation of Affairs (Sachlage) In: HILL, C. O.; HADDOCK, G. E. R. Husserl or Frege? Meaning, Objectivity and Mathematics. Chicago and La Salle: Open Court, 2000. . Platonism, phenomenology and interderivability. In: HARTIMO, M. (edit.). Phenomenology and Mathematics. Dordrecht: Springer Netherlands, 2010 (Phaenomenologica 195).

HARDY, L. Nature's suit: Husserl's phenomenological philosophy and the physical sciences. Athens: Ohio University Press, 2013.

HEFFERNAN, G. Fenomenología de la evidencia. Escritos de Filosofía. Segunda Serie. Buenos Aires: Centro de Estudios Filosóficos Eugenio Pucciarelli. No 2: 3-70 2014.

HUSSERL, E. Investigações lógicas - VI investigação lógica: elementos para uma elucidação fenomenológica do conhecimento. São Paulo: Abril Cultural, 1979.

. Investigaciones lógicas - I Tomo. Segunda

Edición. Madrid: Revista de Occidente, 1967a.

. Investigaciones lógicas - II Tomo. Segunda Edición. Madrid: Revista de Occidente, 1967b.

. Logical investigations - Volume II. New York: Routledge and Kegan Paul, 2001.

MILNAR, I. A. La evidencia en los Prolegómenos y las Investigaciones Lógicas. Primeros aportes para una comprensión modal de la evidencia en Husserl. Investigaciones Fenomenológicas. no 11, pp. 33-56, 2014.
NENON, T. Two models of foundation in the Logical Investigations. In: HOPKINS, B. C. (edit.). Husserl in contemporary context - prospects and projects for phenomenology. Dordrecht: Kluwer Academic Publishers, 1997 (Contributions to Phenomenology - Volume 26).

PIETERSMA, H. Phenomenological epistemology. New York: Oxford University Press, 2000.

PORTA, M. A. G. Husserl: psicologismo, psicologia e fenomenologia. São Paulo: Loyola, 2013.

ROLLINGER, R. D. Names, statements, and their corresponding acts in Husserl's Logical Investigations. In: FISETTE, D. Logical Investigations reconsidered Dordrecht: Kluwer Academic Publishers, 2003 (Contributions to Phenomenology - Volume 48).

STRÖKER, E. (Org.). The husserlian foundations of science. Dordrecht: Kluwer Academic Publishers, 1997 (Contributions to Phenomenology - Volume 30). 